\title{
Contribution of Serum Lipid Profiles to Outcome After Endovascular Thrombectomy for Anterior Circulation Ischemic Stroke
}

\author{
Slaven Pikija ${ }^{1}$ - Laszlo K. Sztriha ${ }^{2}$ - Monika Killer-Oberpfalzer ${ }^{3}$. Friedrich Weymayr ${ }^{4}$ - Constantin Hecker ${ }^{1}$. \\ Christian Ramesmayer ${ }^{1}$ • Larissa Hauer ${ }^{5}$ • Johann Sellner ${ }^{1,6}$ (DD
}

Received: 16 July 2018 / Accepted: 11 October 2018 / Published online: 23 October 2018

(C) The Author(s) 2018

\begin{abstract}
The contribution of lipids, including low- and high-density lipoprotein cholesterol (LDL-C and HDL-C, respectively) and triglycerides (TG), to stroke outcomes is still debated. We sought to determine the impact of LDL-C concentrations on the outcome of patients with ischemic stroke in the anterior circulation who received treatment with endovascular thrombectomy (EVT). We performed a retrospective analysis of consecutive patients with acute ischemic stroke treated at a tertiary center between 2012 and 2016. Patients treated with EVT for large artery occlusion in the anterior circulation were selected. The primary endpoint was functional outcome at 3 months as measured with the modified Rankin Scale (mRS). Secondary outcome measures included hospital death and final infarct volume (FIV). Blood lipid levels were determined in a fasting state, 1 day after admission. We studied a total of 174 patients (44.8\% men) with a median age of 74 years (interquartile range [IQR] 61-82) and median National Institutes of Health Stroke Scale at admission of 18 (14-22). Bridging therapy with intravenous tissue-plasminogen activator (t-PA) was administered in 122 (70.5\%). The median LDL-C was $90 \mathrm{mg} / \mathrm{dl}$ (72-115). LDL-C demonstrated a U-type relationship with FIV $(p=0.036)$. Eighty-three $(50.0 \%)$ patients had an mRS of $0-2$ at 3 months. This favorable outcome was independently associated with younger age (OR $0.944,95 \%$ CI $0.90-0.99, p=0.012)$, thrombolysis in cerebral infarction $2 \mathrm{~b}-3$ reperfusion (OR 5.12, 95\% CI 1.01-25.80, $p=0.015$ ), smaller FIV $\left(0.97\right.$ per $\mathrm{cm}^{3}, 95 \%$ CI $\left.0.97-0.99, p<0.001\right)$, good leptomeningeal collaterals (OR 5.29, $95 \%$ CI 1.48-18.9, $p=0.011)$, and LDL-C more than $77 \mathrm{mg} / \mathrm{dl}$ (OR 0.179, 95\% CI 0.04-0.74, $p=0.018)$. A higher LDL-C concentration early in the course of a stroke caused by large artery occlusion in the anterior circulation is independently associated with a favorable clinical outcome at 3 months. Further studies into the pathophysiological mechanisms underlying this observation are warranted.
\end{abstract}

Keywords Ischemic stroke $\cdot$ Cholesterol $\cdot$ Low-density lipoprotein $\cdot$ Thrombectomy $\cdot$ Outcome

Electronic supplementary material The online version of this article (https://doi.org/10.1007/s12035-018-1391-3) contains supplementary material, which is available to authorized users.

Johann Sellner

j.sellner@salk.at

1 Department of Neurology, Christian Doppler Medical Center, Paracelsus Medical University, Ignaz-Harrer-Straße 79, 5020 Salzburg, Austria

2 Department of Neurology, King's College Hospital, Denmark Hill, London, UK

3 Research Institute for Neurointervention, Christian Doppler Medical Center, Paracelsus Medical University, Salzburg, Austria

4 Division of Neuroradiology, Christian Doppler Medical Center, Paracelsus Medical University, Salzburg, Austria

5 Department of Psychiatry, Psychotherapy and Psychosomatics, Christian Doppler Medical Center, Paracelsus Medical University, Salzburg, Austria

6 Department of Neurology, Klinikum rechts der Isar, Technische Universität München, Munich, Germany

\section{Introduction}

Stroke continues to be major health burden around the world [1]. The INTERSTROKE study revealed that 10 modifiable risk factors account for $90 \%$ of strokes globally, with hypertension ranked as the most important one [2]. Further studies of modifiable factors that influence outcome are very much needed in basic science, translational, and clinical research.

Hyperlipidemia is among the major risk factors for adverse outcome in cardio- and cerebrovascular diseases. Indeed, current guidelines strongly recommend the control of total cholesterol (TC) and low-density cholesterol (LDL-C) levels in order to lower the risk of atherosclerosis and subsequent stroke [3]. Interestingly, studies trying to establish a simple linear relationship between TC, LDL-C, and stroke have revealed conflicting data. Several studies have found that lower TC in patients with acute ischemic stroke is associated with more severe disease and unfavorable outcomes [4-9]. 
Nevertheless, studies showing a positive effect of TC lowering on the risk for the development and progression of cardioand cerebrovascular diseases are numerous [10]. Moreover, prior statin intake resulted in better functional outcome and decreased mortality after ischemic stroke [11-13]. In patients treated with thrombolysis for acute cerebral ischemia, independent predictors of 3-month mortality were lower HDL-C and triglyceride levels [14]. Importantly, a recent study demonstrated a U-curve relationship of TC where a lower frequency of prior ischemic stroke was associated with a high cholesterol level of $\leq 5.5 \mathrm{mmol} / \mathrm{l}$ on admission [15]. The opposite relationship was identified for patients with cholesterol $>$ $5.5 \mathrm{mmol} / \mathrm{l}$. Thus, cholesterol may be a factor contributing to both protective and detrimental mechanisms of action in acute ischemic stroke.

Therefore, we aimed to clarify the impact of the serum lipid profile on outcomes in acute ischemic stroke, and selected a cohort of patients undergoing endovascular therapy (EVT) for large artery occlusion in the anterior circulation.

\section{Subjects and Methods}

We performed a retrospective review of all consecutive stroke patients admitted to Christian Doppler Medical Center, a tertiary hospital in Salzburg, Austria. The protocol was in accordance with the ethics guidance of our hospital's Committee for the Protection of Human Subjects (Protocol UN 2553). According to Austrian regulations, informed consent is not required for the routine collection of clinical and radiological data as used in this study. A written approval for the retrospective analysis of data of patients with acute ischemic stroke was obtained from the local Ethics Committee (415-EP/73/750-2017).

The study period was 2012-2016 with inclusion criteria as follows: $\geq 18$ years of age, CT angiography (CTA) or MR angiography (MRA) confirmed internal carotid artery (ICA), and/or middle cerebral artery (MCA) occlusion within $6 \mathrm{~h}$ of symptom onset, and EVT was performed with a stent retriever. Blood lipids (including LDL-C) were determined the day after admission in a fasting state. EVT was conducted according to the standard operating procedures of our center, implemented on the basis of available high-level evidence. Details of the scanners, imaging protocols, and methodology for determining the size of the hyperdense MCA thrombus were reported previously [16]. Extensive stroke diagnostic workup was performed in all patients, including 24-h ECG (or 72-h ECG when indicated), transthoracic, and, when needed, transesophageal cardiac ultrasound, neurovascular ultrasound of the extracranial and intracranial vessels, and autoimmune and thrombophilia panels as required. The etiology of stroke was established as per the Trial of Org 10172 in Acute Stroke (TOAST) criteria [17]. A detailed timeline of intravenous thrombolysis (IVT) and EVT was recorded as well as the outcome of the recanalization attempt using the thrombolysis in cerebral infarction (TICI) score (TICI). Follow-up CT/MRI within $24 \mathrm{~h}$ after EVT was used to determine the presence of intracerebral hemorrhage (ICH). Follow-up CT scans performed between $24 \mathrm{~h}$ and 7 days were examined to determine the final infarct volume (FIV) or any additional hemorrhagic complications. The infarct area was manually delineated on each CT slice (4 mm thickness) producing an area in square centimeters. Finally, the volume in cubic centimeters was derived from the measured area and the corresponding slice thickness [18]. Additional variables included demographic and laboratory data, leukocyte (neutrophil and lymphocyte) count on admission, National Institutes of Health Stroke Scale (NIHSS) on admission, and the modified Rankin Scale (mRS) at 3 months. The neutrophil count was divided with the leukocyte count to derive the neutrophil-to-lymphocyte ratio (NLR).

Patients were divided into groups of successful (TICI score $2 \mathrm{~b}$ or 3 ) or unsuccessful (TICI score 0,1 , or $2 \mathrm{a}$ ) recanalization.

Leptomeningeal collateral supply was assessed on preprocedural CT angiography. We used a three-category scoring system adapted from [19]: 0-absence of collaterals in the symptomatic hemisphere, 1-less visibility of collaterals in the symptomatic hemisphere, and 2-equal or greater than the contralateral hemisphere.

We defined intracranial hemorrhage (ICH) as per the Heidelberg Bleeding Classification [20]. Patients in whom intracranial hemorrhage was clearly associated with the procedure itself (procedure-related ICH), such as due to vessel perforation, were not accounted for in the ICH group.

\section{Statistical Analysis}

Patient demographics were summarized using descriptive statistics. Depending on the normality of distribution (as tested by the Kolmogorov-Smirnov test), continuous variables were compared using the $t$ test for independent samples, or the Mann-Whitney $U$ test. Categorical variables were compared using Fisher's exact or the chi-square test, as appropriate. For the multivariate analyses, binary logistic regression was performed to calculate odds ratios. The covariates were continuous unless stated otherwise: age, NIHSS at admission, leptomeningeal vascularity (binary), thrombectomy outcome (binary), FIV in cubic centimeters, and history of statin use (binary). A $p$ value of 0.05 was used as threshold for statistical significance. All statistical analyses were performed using STATA software 13.0 (StataCorp LLC, TX, USA).

\section{Results}

Of the 204 patients receiving EVT for large artery anterior circulation stroke, we identified 174 (85.2\%) who had fasting blood lipids, including LDL-C, available. The median age of 
these patients was 74 years (interquartile range [IQR] 61-82), $78(44.8 \%)$ were men, and the median NIHSS score was 18 (IQR 14-22). Pre-treatment with iv t-PA was administered in 122 (70.5\%). The median fasting LDL-C was $90 \mathrm{mg} / \mathrm{dl}$ (IQR 72-115). More detailed baseline characteristics are shown in Supplemental Table S1.

A total of 60 (34.7\%) patients were pre-treated with a statin medication. We found that patients with a fasting LDL above normal range (>100 mg/dl, 41.4\%) were more likely to have been pre-treated with statins ( 58.3 vs. $32.7 \%, p=0.002$ ).

In all patients, a stent retriever-based procedure was applied. There were 40 (22.9\%) ICA + MCA tandem occlusions. Acute stenting of an ICA occlusion was performed in 16 $(32.0 \%)$ patients. Successful reperfusion, defined as TICI grade $2 \mathrm{~b}$ or 3 , was achieved in $129(75.0 \%)$. Symptomatic hemorrhage occurred in 17 (9.8\%). Good outcome (mRS 02) was present in 83 (50.0\%) patients.

Patient demographics are shown in Table 1. LDL-C was not associated with FIV, analyzed either as a continuous variable for a linear relationship or as a binary one defined as hyperlipidemia present or absent. However, after grouping LDL-C in tertiles (1st tertile, 20-77; 2nd, 78-105; 3rd, 106$215 \mathrm{mg} / \mathrm{dl}$ ), we found a $U$-shape relationship with FIV ( $p=$ 0.036, Fig. 1). Furthermore, LDL-C was significantly linked with good clinical outcome (mRS $0-2$ ) in a sub-population with good reperfusion (TICI $2 \mathrm{~b}, 3 ; p<0.001$ ), whereas there was no such relationship in cases with miserable reperfusion (TICI 0-2a; $p=0.104$ ).

We did not find an association between fasting LDL-C and NIHSS on admission $(p=0.072)$. LDL-C demonstrated a positive linear correlation with BMI $(p=0.001)$, and a negative such relationship with age $(p<0.001)$. The same was true for TG and age $(p<0.001)$, but not HDL-C where no relationship with age was found. Male gender was associated with higher LDL-C and HDL-C (median LDL-C $101 \mathrm{mg} / \mathrm{dl}$ [IQR 77-124] vs. $86 \mathrm{mg} / \mathrm{dl}$ [IQR 69-107] [ $p=0.023]$ and median HDL-C $41 \mathrm{mg} / \mathrm{dl}$ [IQR 32-47] vs. $50 \mathrm{mg} / \mathrm{dl}$ [IQR 40-59] [ $p<0.001]$ for men and women, respectively). There was no gender difference for TG. Gender did not impact on the outcome. Figure 2 demonstrates clinical outcome as measured by grades of mRS between groups of patients with $\mathrm{LDL}<100 \mathrm{mg} / \mathrm{dl} \mathrm{vs}$. $\geq 100 \mathrm{mg} / \mathrm{dl}$. Further associations between baseline characteristics, previous statin use, and LDL-C (dichotomized as < $100 \mathrm{mg} / \mathrm{dl}$ and $\geq 100 \mathrm{mg} / \mathrm{dl}$ ) are described in Supplemental Tables S2 and S3. There is a significantly greater proportion of good outcome in those with prior statin use $(p<0.049)$ and LDL $>100 \mathrm{mg} / \mathrm{dl}(p<0.001)$.

A multivariate logistic regression analysis showed an independent association of good outcome (mRS 0-2) with younger age (OR $0.944,95 \%$ CI $0.90-0.99, p=0.012)$, TICI $2 b-3$ reperfusion (OR 5.12, 95\% CI 1.01-25.80, $p=0.015)$, smaller final infarct volume $\left(0.97\right.$ per $\mathrm{cm}^{3}, 95 \%$ CI $0.97-0.99, p<$ 0.001 ), good leptomeningeal collaterals (OR 5.29, $95 \%$ CI
Table 1 Demographics and clinical variables of 174 patients treated with endovascular thrombectomy due to large artery anterior stroke. Range or percentages are shown in brackets

\begin{tabular}{|c|c|}
\hline Parameter & Value \\
\hline Age, median (IQR) & $74(61-82)$ \\
\hline Male sex & $78(44.8)$ \\
\hline Hypertension & $110(63.2)$ \\
\hline Diabetes mellitus & $20(11.6)$ \\
\hline Atrial fibrillation & $67(38.5)$ \\
\hline Good outcome at 3 months (data on $n=166$ ) & $83(50)$ \\
\hline Hospital death & $22(12.8)$ \\
\hline \multicolumn{2}{|l|}{ Admission values } \\
\hline Pre-morbid mRS $>1$ & $6(3.4)$ \\
\hline Body mass index & $25.6(22.8-29.0)$ \\
\hline NIHSS & $18(14-22)$ \\
\hline \multicolumn{2}{|l|}{ Occlusion site } \\
\hline MCA M1 & $134(77.0)$ \\
\hline $\mathrm{ICA}+\mathrm{M} 1 / \mathrm{M} 2$ & $40(22.9)$ \\
\hline ASPECTS & $8(8-9)$ \\
\hline Serum glucose & $119(106-138)$ \\
\hline Creatinine & $0.87(0.77-1.07)$ \\
\hline Total cholesterol & $155(128-185)$ \\
\hline LDL & $90(72-115)$ \\
\hline HDL & $44(37-55)$ \\
\hline Triglycerides & $100(75-145)$ \\
\hline Neutrophil to lymphocyte ratio & $3.65(2.13-5.85)$ \\
\hline Hyperdense thrombus area & $22.6(13.6-42.6)$ \\
\hline \multicolumn{2}{|l|}{ Stroke etiology } \\
\hline Cardioembolic & $141(81.0)$ \\
\hline Large artery atherosclerosis + other & $33(18.9)$ \\
\hline \multicolumn{2}{|l|}{ Procedure related } \\
\hline Good leptomeningeal collaterals & $46(29.3)$ \\
\hline Intravenous thrombolysis & $122(70.5)$ \\
\hline Time to first imaging, min & $96(66-137)$ \\
\hline Time to needle & $110(85-150)$ \\
\hline Time to groin puncture & $189(154-237)$ \\
\hline Number of passes $>3$ & $67(47.9)$ \\
\hline Intervention time & $52(23-93)$ \\
\hline ICA Stenting & $16(32.0)$ \\
\hline TICI $2 b$ or 3 & $129(75.0)$ \\
\hline Symptomatic hemorrhage & $17(9.8)$ \\
\hline Final infarct volume & $30.9(4.3-126.5)$ \\
\hline
\end{tabular}

$I Q R$ interquartile range, $m R S$ modified Rankin Scale, ASPECTS Alberta Stroke Program Early CT Score, $L D L$ low-density lipoprotein, $H D L$ highdensity lipoprotein, TICI thrombolysis in cerebral infarction, $M C A$ middle cerebral artery, ICA internal cerebral artery

$1.48-18.9, p=0.011)$, and LDL-C more than $77 \mathrm{mg} / \mathrm{dl}(\mathrm{OR}$ $0.179,95 \%$ CI $0.04-0.74, p=0.018$ ) (Table 2).

When the same covariates were tested for FIV under $151 \mathrm{~cm}^{3}$ (i.e., 75th percentile), the total and 2nd tertile of 
Fig. $1 U$-shape relationship of low-density lipoprotein with infarct volume in patients treated for large artery anterior stroke with endovascular thrombectomy

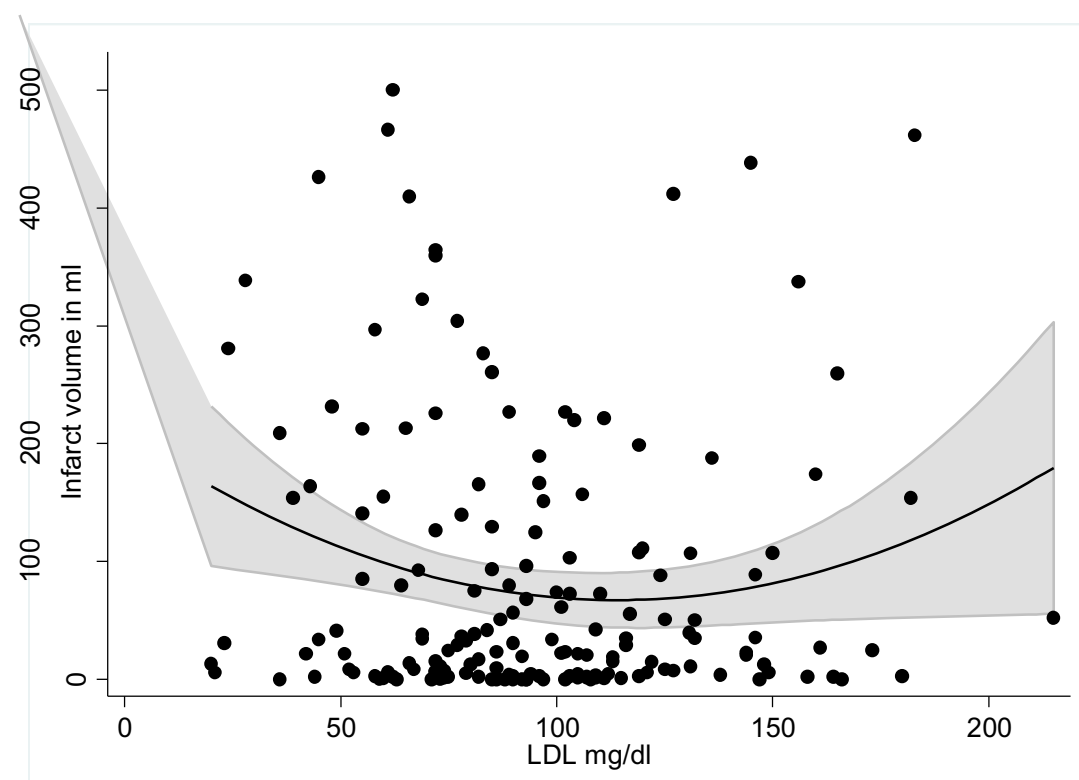

LDL concentrations were independently associated with lower FIV, OR 3.17 (95\% CI 1.17-8.54, $p=0.022$ ), reflecting a $U$-relationship with FIV.

\section{Discussion}

In this single-center study of acute ischemic stroke treated with EVT for large artery occlusion in the anterior circulation, high serum levels of LDL-C were independently associated with a better clinical outcome at 3 months. Furthermore, LDLC showed a $U$-shape relationship with FIV, which provides a possible explanation for the previously seen ambiguity of reports on the prognostic relevance of cholesterol in acute ischemic stroke. Several previous studies have identified an association of high cholesterol levels with better stroke outcomes. Conversely, a protective effect of pre-stroke statin use in the acute phase of stroke has also been reported (Table 3).
Stroke risk, mainly of atherothrombotic infarction [24], has been found to be elevated in those with high TC [21-23]. The favorable effects of statins include plaque stabilization and reduction of microembolism from large artery atherosclerosis [24]. While such anti-inflammatory effects of statins are beneficial, high LDL-C of $>130 \mathrm{mg} / \mathrm{dl}$ was not found to carry an increased risk of stroke in another study; therefore, more complex interactions are presumably in place [25]. In this regard, Bringeland et al. reported a $U$-curve relationship between the relative frequency of prior ischemic stroke and cholesterol level [15]. Lower frequency of prior ischemic stroke was associated with a high cholesterol level of up to $5.5 \mathrm{mmol} / \mathrm{l}$ on admission. Cholesterol levels higher than this, in contrast, were associated with an increased frequency of stroke. Of note, the $U$-type relationship with FIV in our cohort was more pronounced in statin-naïve patients. The potential relevance of cholesterol levels to recovery was also suggested by a study by Lai et al., who found that higher total cholesterol in the acute phase of ischemic stroke was a favorable prognostic

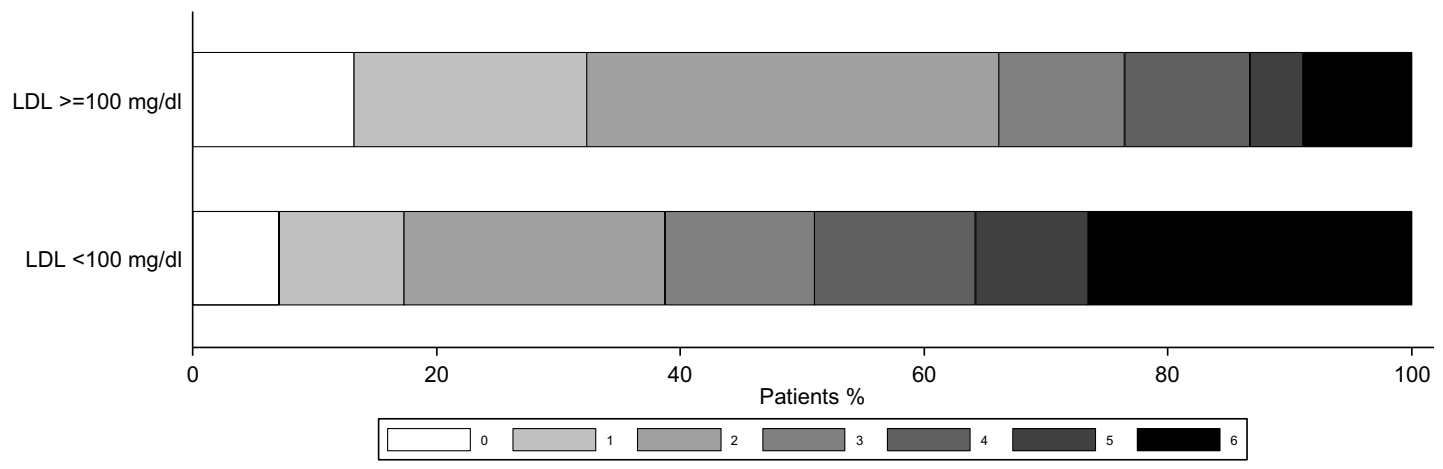

Fig. 2 mRS outcomes at 3 months according to low or high LDL-C levels in 174 patients treated with endovascular thrombectomy for large artery anterior circulation stroke 
Table 2 Multivariate analysis of determinants for good clinical outcome (mRS 0-2)

Good outcome, $\mathrm{mRS}=0-2$

\begin{tabular}{llll}
\hline & $\begin{array}{l}\text { Odds } \\
\text { ratio }\end{array}$ & $\begin{array}{l}\text { 95\% Confidence } \\
\text { interval }\end{array}$ & $p$ value \\
\hline Age, per year & 0.944 & $0.902-0.987$ & 0.012 \\
NIHSS, per point & 0.941 & $0.855-1.035$ & 0.211 \\
TICI 2b-3 reperfusion & 5.119 & $1.015-25.801$ & 0.015 \\
LDL 20-77 mg/dl vs. ref. & 0.179 & $0.043-0.742$ & 0.018 \\
LDL 78-105 mg/dl (ref.) & & & \\
LDL 106-215 mg/dl vs. ref. & 1.593 & $0.496-5.109$ & 0.434 \\
Glucose 79-109 mg/dl vs. ref. & 3.939 & $0.943-16.377$ & 0.060 \\
Glucose 110-130 mg/dl (ref.) & & & \\
Glucose 110-130 mg/dl vs. ref. & 0.911 & $0.281-2.952$ & 0.878 \\
Final infarct volume in cm & 0.976 & $0.966-0.987$ & $<0.001$ \\
Good leptomeningeal collaterals & 5.296 & $1.476-18.998$ & 0.011 \\
\hline
\end{tabular}

$v s$. versus, Ref. reference

factor for long-term motor function [26]. Another U-curve relationship of TC with total stroke death was reported by Iso et al. [27], with the highest rate of total stroke death occurring in patients with $\mathrm{TC}<160 \mathrm{mg} / \mathrm{dl}$. Koton et al. showed that patients with $\mathrm{TC} \leq 115 \mathrm{mg} / \mathrm{dl}$ are at risk of increased stroke severity and poorer functional outcome regardless of pre-stroke statin use [4]. They also found short- and long-term mortality rates to be increased in patients with $\mathrm{TC} \leq 115 \mathrm{mg} /$ dl. In our cohort of patients in the 3rd tertile (LDL-C > $105 \mathrm{mg} / \mathrm{dl}$ ), strokes were less severe at onset; however, such a relationship was not found for TC. In a previous study, a TC level above $117 \mathrm{mg} / \mathrm{dl}(6.5 \mathrm{mmol} / \mathrm{l})$ was associated with better early functional outcome at 1 month. [7]. In the Copenhagen Stroke Study, higher TC levels were associated with less severe strokes and all-cause mortality in 500 patients [6]. The effect of higher TC on improved outcome is confirmed across different stroke etiologies [7]. An analysis of 1256 exclusively atherothrombotic first-ever strokes [28] found higher dependency and recurrence rates in patients in the lowest quintile of TC after 36 months; however, no effect on mortality rates between the TC quintiles was seen. Since our population consisted of $81 \%$ cardioembolic or presumedcardioembolic stroke etiologies, direct comparison with this study is difficult.

The effect of pre-stroke statin therapy on stroke severity at admission and FIV was not observed in our population; however, we did demonstrate better outcomes at 3 months in those taking a statin $(p=0.013)$. Therefore, we were able to corroborate results of previous studies that showed statin treatment at stroke onset to be linked with favorable outcome at 90 days [29].

Whether statin treatment and cholesterol levels are risk factors for intracerebral hemorrhage is debated. A few large prospective studies (SPARCL, HPS, Cochrane review) found an elevated risk for ICH in statin users [30, 31]. However, other studies disagreed $[32,33]$. A recent large registry analysis of 345,531 patients showed a lower incidence of ICH in statin users and in patients with higher cholesterol [34].

Under normal circumstances, TC metabolism is compartmentalized in the brain with no interchange with the systemic TC pool [35]. However, in pathologic states, such as when the blood-brain-barrier is disrupted by ischemia, TC could enhance repair and remyelination of penumbral tissue. Indeed, in our population, patients with good reperfusion after EVT showed association of LDL-C levels with good outcome, whereas such a relationship was not seen in those with miserable reperfusion. TC could also act as a buffer for free radicals released during ischemic injury, and therefore limit the extension of infarction [36]. The beneficial role of cholesterol for limiting brain injury is further supported by a recent study which reported increased hemorrhagic transformation in ischemic stroke patients who had low LDL levels [28].

Some shortcomings of our study include its retrospective design, lack of LDL-C measurement in $15 \%$ of our patients, and lack of information on other potential factors that could be present in patients with low LDL-C, such as decreased factor VII and albumin levels [37]. However, we did control for
Table 3 Differences of outcome surrogates depending on fasting low-density lipoprotein levels and hyperlipidemia (defined as $\mathrm{LDL} \geq 100 \mathrm{mg} / \mathrm{dl})$

\begin{tabular}{llll}
\hline & \multicolumn{2}{l}{ Fasting LDL $(\mathrm{mg} / \mathrm{dl}$, median[IQR] $)$} & \\
mRS at 3 months & $0-2(n=83)$ & $3-6(n=83)$ & $p$ value \\
& $105(85-124)$ & $78(62-102)$ & $<0.001$ \\
Hospital death & No $(n=152)$ & Yes $(n=22)$ & 0.002 \\
& $93(74-119)$ & $69(45-93)$ & \\
Outcome & Presence of hyperlipidemia & & $p$ value \\
mRS 0-2 at 3 months $(\mathrm{n}=83)$ & Present $(\%)$ & Absent $(\%)$ & 0.001 \\
Hospital death $(n=22)$ & $45(54.2)$ & $23(27.7)$ & 0.066 \\
Final infarct volume $\left(\mathrm{cm}^{3}\right)$ & $5(22.7)$ & $17(77.3)$ & 0.702 \\
\hline
\end{tabular}

Interval variables between groups were compared using the non-parametric Kruskal-Wallis test and comparisons between proportions using Fisher's exact test 
diabetes which also is associated with low LDL-C. We also controlled for heart failure, renal function, and body mass index. Demographics, initial stroke severity, and hospital death in our study are comparable with the findings of recently published large EVT trials. For example, NIHSS at presentation in our study (18 [IQR 14-22]) was similar to a recently published meta-analysis (NIHSS 17 [IQR 14-20]) [38]. Favorable outcome, as indicated by an mRS score of $0-2$ at 3 months, was achieved in $50.0 \%$ of our patients, similar to the $46.0 \%$ reported in major trials. A mortality of $12.8 \%$ in our population also compares favorably with published data $(15.3 \%)$ by Goyal et al.

In conclusion, in patients with ischemic stroke due to occlusion of a large artery in the anterior circulation of mainly cardioembolic etiology, LDL-C independently predicts outcome at 3 months, and has a $U$-curve relationship with final infarct volume. Further studies are needed to investigate the role of LDL-C in acute ischemic stroke.

Acknowledgements The authors thank Prof. Eugen Trinka for his continuous support.

Funding Information Open access funding provided by Paracelsus Medical University.

\section{Compliance with Ethical Standards}

Conflicts of Interest The authors declare that they have no conflict of interest.

Open Access This article is distributed under the terms of the Creative Commons Attribution 4.0 International License (http:// creativecommons.org/licenses/by/4.0/), which permits unrestricted use, distribution, and reproduction in any medium, provided you give appropriate credit to the original author(s) and the source, provide a link to the Creative Commons license, and indicate if changes were made.

\section{References}

1. Feigin VL, Norrving B, Mensah GA (2017) Global burden of stroke. Circ Res 120(3):439-448. https://doi.org/10.1161/ CIRCRESAHA.116.308413

2. O'Donnell MJ, Chin SL, Rangarajan S, Xavier D, Liu L, Zhang $\mathrm{H}$, Rao-Melacini P, Zhang X et al (2016) Global and regional effects of potentially modifiable risk factors associated with acute stroke in 32 countries (INTERSTROKE): a case-control study. Lancet 388(10046):761-775. https://doi.org/10.1016/ S0140-6736(16)30506-2

3. Nayor M, Vasan RS (2016) Recent update to the US cholesterol treatment guidelines: a comparison with international guidelines. Circulation 133(18):1795-1806. https://doi.org/10.1161/ CIRCULATIONAHA.116.021407

4. Koton S, Molshatzki N, Bornstein NM, Tanne D (2012) Low cholesterol, statins and outcomes in patients with first-ever acute ischemic stroke. Cerebrovasc Dis 34(3):213-220. https://doi.org/10. $1159 / 000342302$
5. Markaki I, Nilsson U, Kostulas K, Sjostrand C (2014) High cholesterol levels are associated with improved long-term survival after acute ischemic stroke. J Stroke Cerebrovasc Dis 23(1):e47-e53. https://doi.org/10.1016/j.jstrokecerebrovasdis.2013.08.009

6. Olsen TS, Christensen RH, Kammersgaard LP, Andersen KK (2007) Higher total serum cholesterol levels are associated with less severe strokes and lower all-cause mortality: ten-year follow-up of ischemic strokes in the Copenhagen Stroke Study. Stroke 38(10): 2646-2651. https://doi.org/10.1161/STROKEAHA.107.490292

7. Vauthey C, de Freitas GR, van Melle G, Devuyst G, Bogousslavsky J (2000) Better outcome after stroke with higher serum cholesterol levels. Neurology 54(10):1944-1949

8. Zuliani G, Cherubini A, Atti AR, Ble A, Vavalle C, Di Todaro F, Benedetti C, Volpato S et al (2004) Low cholesterol levels are associated with short-term mortality in older patients with ischemic stroke. J Gerontol A Biol Sci Med Sci 59(3):293-297

9. Pikija S, Trkulja V, Juvan L, Ivanec M, Duksi D (2013) Higher onadmission serum triglycerides predict less severe disability and lower all-cause mortality after acute ischemic stroke. J Stroke Cerebrovasc Dis 22(7):e15-e24. https://doi.org/10.1016/j. jstrokecerebrovasdis.2012.03.006

10. Castilla-Guerra L, Del Carmen Fernandez-Moreno M, ColmeneroCamacho MA (2016) Statins in stroke prevention: present and future. Curr Pharm Des 22(30):4638-4644

11. Stead LG, Vaidyanathan L, Kumar G, Bellolio MF, Brown RD Jr, Suravaram S, Enduri S, Gilmore RM et al (2009) Statins in ischemic stroke: just low-density lipoprotein lowering or more? J Stroke Cerebrovasc Dis 18(2):124-127. https://doi.org/10.1016/j. jstrokecerebrovasdis.2008.09.016

12. Elkind MS, Flint AC, Sciacca RR, Sacco RL (2005) Lipid-lowering agent use at ischemic stroke onset is associated with decreased mortality. Neurology 65(2):253-258. https://doi.org/10.1212/01. wnl.0000171746.63844.6a

13. Hjalmarsson C, Bokemark L, Manhem K, Mehlig K, Andersson B (2012) The effect of statins on acute and long-term outcome after ischemic stroke in the elderly. Am J Geriatr Pharmacother 10(5): 313-322. https://doi.org/10.1016/j.amjopharm.2012.09.001

14. Nardi K, Engelter S, Strbian D, Sarikaya H, Arnold M, Casoni F, Ford GA, Cordonnier $\mathrm{C}$ et al (2012) Lipid profiles and outcome in patients treated by intravenous thrombolysis for cerebral ischemia. Neurology 79(11):1101-1108. https://doi.org/10.1212/WNL. 0b013e3182608c 82

15. Bringeland GH, Nacu A, Waje-Andreassen U, Thomassen L, Naess H (2016) U-curve relation between cholesterol and prior ischemic stroke. Brain Behav 6(11):e00574. https://doi.org/10. 1002/brb3.574

16. Pikija S, Magdic J, Lukic A, Schreiber C, Mutzenbach JS, McCoy MR, Sellner J (2016) Antiplatelet usage impacts clot density in acute anterior circulation ischemic stroke. Int J Mol Sci 17(9). https://doi.org/10.3390/ijms17091382

17. Adams HP,J, Bendixen BH, Kappelle LJ, Biller J, Love BB, Gordon DL, Marsh EE 3rd (1993) Classification of subtype of acute ischemic stroke. Definitions for use in a multicenter clinical trial. TOAST. Trial of Org 10172 in Acute Stroke Treatment. Stroke 24(1):35-41

18. Pikija S, Trkulja V, Mutzenbach JS, McCoy MR, Ganger P, Sellner J (2016) Fibrinogen consumption is related to intracranial clot burden in acute ischemic stroke: a retrospective hyperdense artery study. J Transl Med 14(1):250. https://doi.org/10.1186/s12967016-1006-6

19. Lima FO, Furie KL, Silva GS, Lev MH, Camargo EC, Singhal AB, Harris GJ, Halpern EF et al (2010) The pattern of leptomeningeal collaterals on CT angiography is a strong predictor of long-term functional outcome in stroke patients with large vessel intracranial occlusion. Stroke 41(10):2316-2322. https://doi.org/10.1161/ STROKEAHA.110.592303 
20. von Kummer R, Broderick JP, Campbell BC, Demchuk A, Goyal M, Hill MD, Treurniet KM, Majoie CB et al (2015) The Heidelberg bleeding classification: classification of bleeding events after ischemic stroke and reperfusion therapy. Stroke 46(10):2981-2986. https://doi.org/10.1161/STROKEAHA.115.010049

21. Horenstein RB, Smith DE, Mosca L (2002) Cholesterol predicts stroke mortality in the Women's Pooling Project. Stroke 33(7): $1863-1868$

22. Kurth T, Everett BM, Buring JE, Kase CS, Ridker PM, Gaziano JM (2007) Lipid levels and the risk of ischemic stroke in women. Neurology 68(8):556-562. https://doi.org/10.1212/01.wnl. $0000254472.41810 .0 \mathrm{~d}$

23. Harmsen P, Lappas G, Rosengren A, Wilhelmsen L (2006) Longterm risk factors for stroke: twenty-eight years of follow-up of 7457 middle-aged men in Goteborg, Sweden. Stroke 37(7):1663-1667. https://doi.org/10.1161/01.STR.0000226604.10877.fc

24. Safouris A, Krogias C, Sharma VK, Katsanos AH, Faissner S, Roussopoulou A, Zompola C, Kneiphof J et al (2017) Statin pretreatment and microembolic signals in large artery atherosclerosis. Arterioscler Thromb Vasc Biol 37(7):1415-1422. https://doi.org/ 10.1161/ATVBAHA.117.309292

25. Willey JZ, Xu Q, Boden-Albala B, Paik MC, Moon YP, Sacco RL, Elkind MS (2009) Lipid profile components and risk of ischemic stroke: the Northern Manhattan Study (NOMAS). Arch Neurol 66(11):1400-1406. https://doi.org/10.1001/archneurol.2009.210

26. Lai YT, Hsieh CL, Lee HP, Pan SL (2012) Are higher total serum cholesterol levels associated with better long-term motor function after ischemic stroke? Nutr Neurosci 15(6):239-243. https://doi. org/10.1179/1476830512Y.0000000016

27. Iso H, Jacobs DR Jr, Wentworth D, Neaton JD, Cohen JD (1989) Serum cholesterol levels and six-year mortality from stroke in 350 , 977 men screened for the multiple risk factor intervention trial. $\mathrm{N}$ Eng1 J Med 320(14):904-910. https://doi.org/10.1056/ NEJM198904063201405

28. Zhao W, An Z, Hong Y, Zhou G, Guo J, Zhang Y, Yang Y, Ning X et al (2016) Low total cholesterol level is the independent predictor of poor outcomes in patients with acute ischemic stroke: a hospitalbased prospective study. BMC Neurol 16:36. https://doi.org/10. 1186/s12883-016-0561-z

29. Ni Chroinin D, Asplund K, Asberg S, Callaly E, Cuadrado-Godia E, Diez-Tejedor E, Di Napoli M, Engelter ST et al (2013) Statin therapy and outcome after ischemic stroke: systematic review and meta-analysis of observational studies and randomized trials. Stroke 44(2):448-456. https://doi.org/10.1161/STROKEAHA. 112.668277

30. Amarenco P, Bogousslavsky J, Callahan A 3rd, Goldstein LB, Hennerici M, Rudolph AE, Sillesen H, Simunovic L et al (2006) High-dose atorvastatin after stroke or transient ischemic attack. N Engl J Med 355(6):549-559. https://doi.org/10.1056/ NEJMoa061894

31. Vergouwen MD, de Haan RJ, Vermeulen M, Roos YB (2008) Statin treatment and the occurrence of hemorrhagic stroke in patients with a history of cerebrovascular disease. Stroke 39(2):497-502. https:// doi.org/10.1161/STROKEAHA.107.488791

32. McKinney JS, Kostis WJ (2012) Statin therapy and the risk of intracerebral hemorrhage: a meta-analysis of 31 randomized controlled trials. Stroke 43(8):2149-2156. https://doi.org/10.1161/ STROKEAHA.112.655894

33. Hackam DG, Woodward M, Newby LK, Bhatt DL, Shao M, Smith EE, Donner A, Mamdani M et al (2011) Statins and intracerebral hemorrhage: collaborative systematic review and meta-analysis. Circulation 124(20):2233-2242. https://doi.org/10.1161/ CIRCULATIONAHA.111.055269

34. Saliba W, Rennert HS, Barnett-Griness O, Gronich N, Molad J, Rennert G, Auriel E (2018) Association of statin use with spontaneous intracerebral hemorrhage: a cohort study. Neurology 91(5): e400-e409. https://doi.org/10.1212/WNL.0000000000005907

35. Czuba E, Steliga A, Lietzau G, Kowianski P (2017) Cholesterol as a modifying agent of the neurovascular unit structure and function under physiological and pathological conditions. Metab Brain Dis 32(4):935-948. https://doi.org/10.1007/s11011-017-0015-3

36. Joseph JA, Villalobos-Molinas R, Denisova NA, Erat S, Strain J (1997) Cholesterol: a two-edged sword in brain aging. Free Radic Biol Med 22(3):455-462

37. Manolio TA, Ettinger WH, Tracy RP, Kuller LH, Borhani NO, Lynch JC, Fried LP (1993) Epidemiology of low cholesterol levels in older adults. The Cardiovascular Health Study. Circulation 87(3): 728-737

38. Goyal M, Menon BK, van Zwam WH, Dippel DW, Mitchell PJ, Demchuk AM, Davalos A, Majoie CB et al (2016) Endovascular thrombectomy after large-vessel ischaemic stroke: a metaanalysis of individual patient data from five randomised trials. Lancet 387(10029):1723-1731. https://doi.org/10.1016/S01406736(16)00163-X 